\title{
Effect of Sulfate Erosion on Multiple Interface Microstructure of Recycled Concrete
}

\author{
Li Qianqian ${ }^{1, \text { a }}$, Li Qiuyi ${ }^{2, b}$ and Guo Yuanxin ${ }^{3, c}$ \\ ${ }^{1}$ Postgraduate, School of Civil Engineering, Qingdao University of Technology, Qingdao, China \\ ${ }^{2}$ Professor, Centre for Durability Studies, Qingdao University of Technology, Qingdao, China \\ ${ }^{3}$ P.h.D., School of Civil Engineering, Qingdao University of Technology, Qingdao, China \\ a Email:457552796@qq.com, ${ }^{\mathrm{b}}$ Email: Iqyyxn@163.com, ${ }^{\mathrm{c}}$ Email: gyxkz@qq.com
}

\begin{abstract}
Keywords: recycled concrete, multiple interface, microhardness, sulfate attack, age
Abstract. By studying the microhardness of different interfaces of sulphate-eroded recycled concrete, the width of the transition zone of different interface from different strength grades was determined. And the influence of sulfate age on the microstructure of regenerated concrete was studied, which reveal the mechanism of deterioration of sulfate erosion in multiple interfaces of recycled concrete. The results show that the microhardness of old aggregate - new slurry interface (LG-XJ interface), old slurry - new slurry interface (LJ-XJ interface) and old aggregate - old slurry interface (LG-LJ interface) with the same strength reclaimed concrete increases firstly and then decreases as the growth of the age of the sulfate, and also the width of the interface transition zone reduces first and then increases. When the erosion age is $60 \mathrm{~d}$, the change of the interfacial transition zone of the LJ-XJ interface that is with high strength grade recycled concrete is still not obvious. And when the erosion age are 90d, the width of the interface transition zone increases. The strength of the three kinds of interface resistance to sulfate attack of recycled concrete with the same strength grade: the LG-XJ interface is the weakest, and the LG-LJ interface is the second, then the LJ-XJ interface is the strongest. With the development of the strength grade of recycled concrete, the microhardness of the same interface heightens and the width of the interface transition zone reduces, what's more, the ability of the interface to resist sulfate attack is enhanced.
\end{abstract}

\section{Introduction}

Recycled concrete as a multi-phase, multi-interface and non-uniform composite material, its durability research is an important part of recycled concrete research, and sulfate erosion is a key part of the research on the durability of recycled concrete ${ }^{[1]}$. Sulfate attack is expansive erosion, and its essence is that the sulfate ions enter the interior of the reclaimed concrete and undergo a series of complex physical and chemical reactions with the hydrated product of the cement to produce a product with a very low solubility, which leads to deterioration of the recycled concrete. The microhardness of different interfaces of recycled concrete with sulphate corrosion was measured by Micro Vickers Hardness Tester to determine the width of the transition zone of different interfaces with different strength recycled concrete. The interface transition area is defined as that the interface between the hardened cement paste and the coarse aggregate in the concrete is a loose porous structure (Interfacial Transition Zone, referred to as ITZ). The effect of sulfate attack age on the microstructure of recycled concrete was studied, and the deterioration mechanism of recycled concrete was observed from the microcosmic level.

Before the researchers carried out the study of the interface structure of recycled concrete, the recycled aggregate was dispersed in the cement slurry to prepare the recycled concrete directly ${ }^{[2,3,4,5]}$. The research method has great uncertainty and blindness, so a new method for the study of recycled concrete interface is needed. In this paper, the multiple interface model of recycled concrete was reconstructed by the method of preparing the original concrete core sample. 


\section{Experimental design}

Test Raw Materials. (1) Cement: the experiment uses P.O 42.5 cement produced by Shanshui Cement Plant. And the basic performance indicators are shown in Table 1.

Table 1 Basic performance indicators of cement

\begin{tabular}{|c|c|c|c|c|c|}
\hline Cement type & \multicolumn{2}{|c|}{$\begin{array}{l}\text { Compressive strength } \\
(\mathrm{Mpa})\end{array}$} & \multicolumn{2}{|c|}{$\begin{array}{l}\text { Flexural strength } \\
(\mathrm{Mpa})\end{array}$} & $\begin{array}{c}\text { Stability(Boiling } \\
\text { process) }\end{array}$ \\
\hline $\mathrm{P} \cdot \mathrm{O} 42.5$ & $\begin{array}{c}3 \mathrm{~d} \\
18.70\end{array}$ & $\begin{array}{c}28 \mathrm{~d} \\
48.20\end{array}$ & $\begin{array}{c}3 \mathrm{~d} \\
4.60\end{array}$ & $\begin{array}{l}28 \mathrm{~d} \\
7.30\end{array}$ & qualified \\
\hline
\end{tabular}

(2) Coarse aggregate: using 5 20mm continuous grading of limestone gravel, technical indicators in Table 2.

Table 2 coarse aggregate technical indicators

\begin{tabular}{cccccc}
\hline $\begin{array}{c}\text { Water } \\
\text { absorption } \\
(\%)\end{array}$ & $\begin{array}{c}\text { Moisture } \\
\text { content } \\
(\%)\end{array}$ & $\begin{array}{c}\text { Needle and } \\
\text { flake content } \\
(\%)\end{array}$ & $\begin{array}{c}\text { Crush index } \\
(\%)\end{array}$ & $\begin{array}{c}\text { Bulk density } \\
\left(\mathrm{kg} / \mathrm{m}^{3}\right)\end{array}$ & $\begin{array}{c}\text { Apparent } \\
\text { density } \\
\left(\mathrm{kg} / \mathrm{m}^{3}\right)\end{array}$ \\
\hline 1.60 & 0.41 & 3.74 & 12.40 & 1450 & 2590 \\
\hline
\end{tabular}

(3) Fine aggregate: natural river sand with a fineness modulus of 2.5.

(4)Admixture: polycarboxylate high performance water reducing agent, water reduction rate of $30 \%$, the amount of $1.2 \%$.

(5)Water: tap water.

Test Mix Ratio. The concrete mix ratio is shown in Table 3.

Table 3 original concrete mix proportion and compressive strength

\begin{tabular}{lllll}
\hline $\begin{array}{l}\text { Strength } \\
\text { grade }\end{array}$ & $\begin{array}{l}\text { Cement } \\
\left(\mathrm{kg} / \mathrm{m}^{3}\right)\end{array}$ & $\begin{array}{l}\text { Fine aggregate } \\
\left(\mathrm{kg} / \mathrm{m}^{3}\right)\end{array}$ & $\begin{array}{l}\text { Coarse aggregate } \\
\left(\mathrm{kg} / \mathrm{m}^{3}\right)\end{array}$ & $\begin{array}{l}\text { Water } \\
\text { binder } \\
\text { ratio }\end{array}$ \\
\hline C30 & 300 & 780 & 1170 & 0.39 \\
C45 & 430 & 724 & 1086 & 0.33 \\
C60 & 550 & 672 & 1008 & 0.31 \\
\hline
\end{tabular}

The coarse aggregate in the original concrete mix ratio is removed, and the original water-cement ratio is reduced by 0.02 , so the mixing ratio of the mortar is obtained.

Test Plan. Recycled concrete multiple interface reconstruction method is to put the waste concrete (prepared in advance of the concrete core sample) in the mortar, through the slices to determine the different interface of recycled concrete. This method solved the problem of the accurate positioning of the interface between the old slurry $(\mathrm{LJ})$ and the cement mortar wrapped with the core $(\mathrm{XJ})$ (referred to as LJ-XJ interface), the interface between the old aggregate( $(\mathrm{G})$ and the new slurry $(\mathrm{XJ})$ ( referred to as LG-XJ interface), and the interface between the old aggregate(LG) and the old slurry(LJ)( referred to as LG-LJ interface).

(1)Preparation of core - like concrete: for comparison, we chose $40 \%$ of the sand rate to prepare the original concrete that its standard size is $100 \mathrm{~mm} \times 600 \mathrm{~mm} \times 800 \mathrm{~mm}$. Then drill $\varphi 75 \mathrm{~mm} \times 100 \mathrm{~mm}$ cylindrical cores after 18 months of standard curing. Place the core sample (soak for 24 hours and rub until dry) in the center of the test mode with a size of $100 \mathrm{~mm} \times 100 \mathrm{~mm} \times 100 \mathrm{~mm}$, pouring cement mortar with the same strength grade as the core-like concrete (as shown in Figure 1(a)). After the specimens are molded, the mold is removed and put them in a standard curing room for further maintenance. 
(2) Specimens were taken out after 28 days and sliced. The sections were $100 \mathrm{~mm} \times 100 \mathrm{~mm} \times 20$ $\mathrm{mm}$ (Figure 1 (b)). The slices were placed in the prepared $5 \% \mathrm{Na}_{2} \mathrm{SO}_{4}$ solution for 30 days, 60 days and 90 days, and the blank control group $(0 \mathrm{~d})$ was set aside. The same concentration of $\mathrm{Na}_{2} \mathrm{SO}_{4}$ solution was changed every two weeks to keep the $\mathrm{pH}$ value constant. After reaching the corresponding soaking age, the microstructures of the LG-LJ interface, the LJ-XJ interface and the LG-XJ interface were measured respectively after the steps such as grinding and polishing.

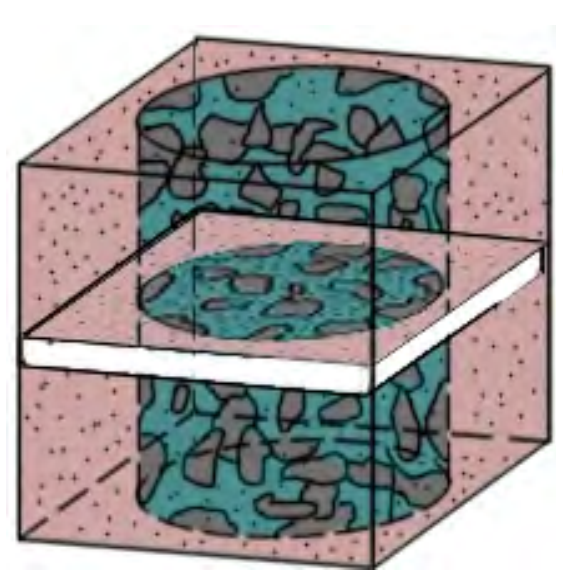

(a)

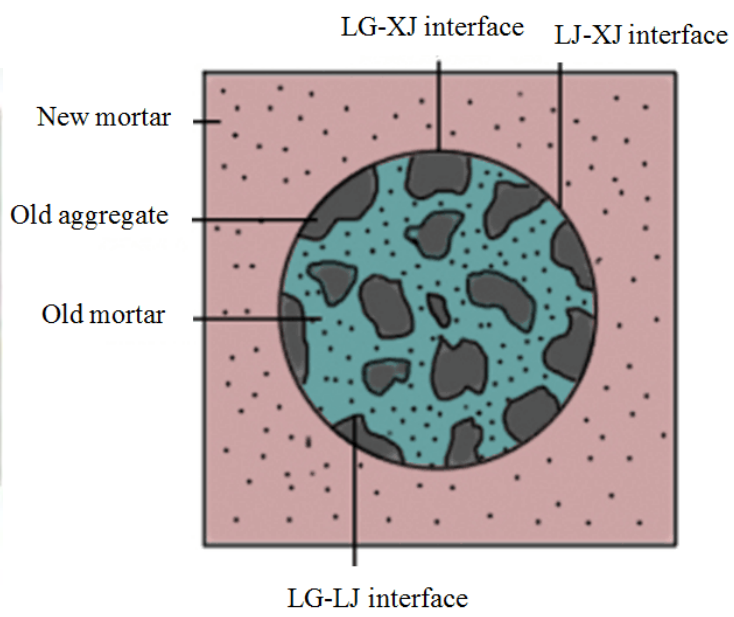

(b)

FIG.1. Schematic diagram of the model for the reconstruction of the interface of recycled concrete

\section{Results and Discussion}

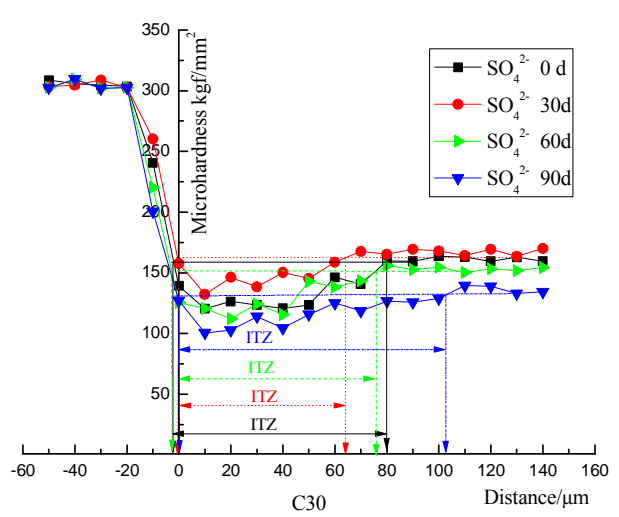

(a)

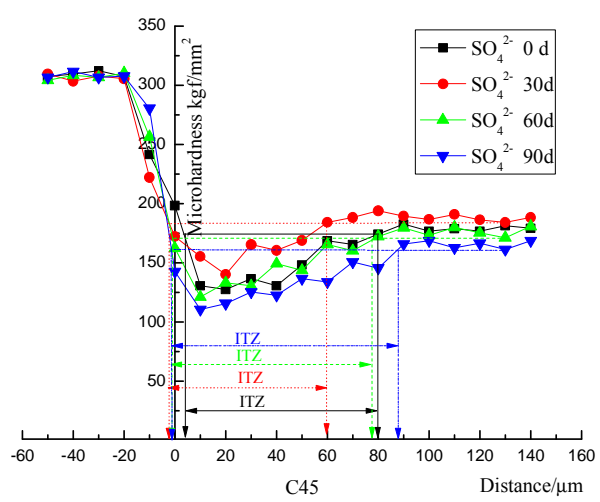

(b)

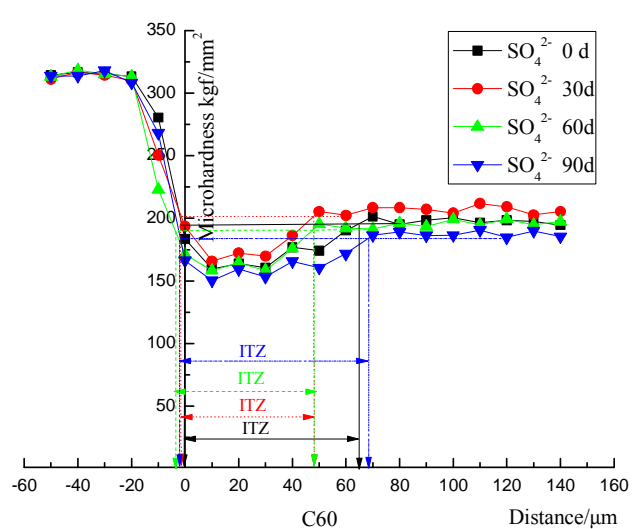

(c)

Fig.2. The variation law of LG-XJ interface micro hardness of recycled concrete 


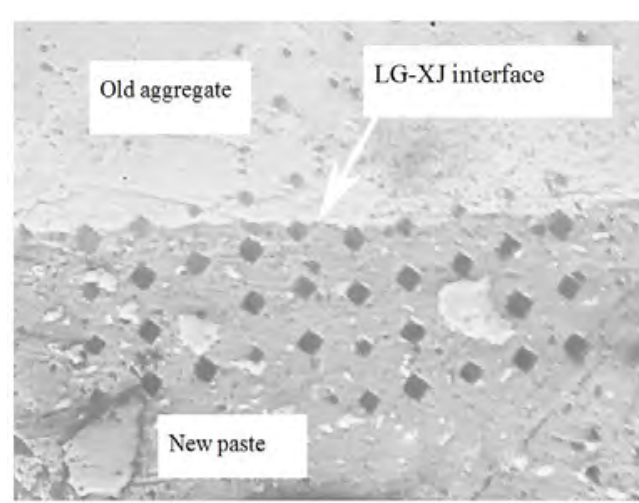

(a) $100 \times$

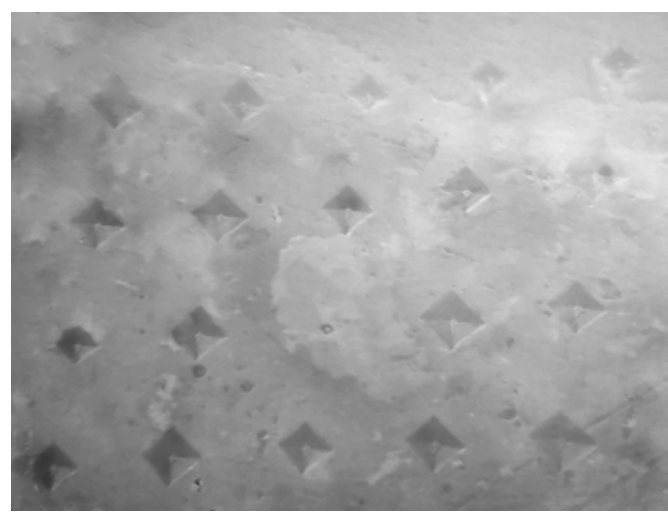

(b) $400 \times$

Fig.3. Optical micrograph of LG-XJ interface hardness of recycled concrete

The Variation Law of LG-XJ Interface Microhardness of Recycled Concrete. It can be seen from Fig. 2 and Fig. 3 that the microhardness of the LG-XJ interface of the regenerated concrete with the same strength is increased firstly and then decreases with the growth of the erosion age, and the width of the interface transition zone reduces first of all and then increases. Taking the LG-XJ interface of C45 recycled concrete as an example, the interfacial microhardness is about 130.6kgf $/ \mathrm{mm}^{2} \sim 174.3 \mathrm{kgf} / \mathrm{mm}^{2}$ and the interfacial transition zone is about $70 \mu \mathrm{m} \sim 75 \mu \mathrm{m}$ when the age of sulfate attack is $0 \mathrm{~d}$. When the sulfate corrosion is $30 \mathrm{~d}$, the interfacial microhardness is about $155.4 \mathrm{kgf}$ $/ \mathrm{mm}^{2} \sim 184.1 \mathrm{kgf} / \mathrm{mm}^{2}$, and the width of interfacial transition zone is about $55 \mu \mathrm{m} \sim 60 \mu \mathrm{m}$. while the sulfate attack is $60 \mathrm{~d}$, the interfacial microhardness is about $121.2 \mathrm{kgf} / \mathrm{mm}^{2} \sim 171.2 \mathrm{kgf} / \mathrm{mm}^{2}$, and the interface transition zone width is about $65 \mu \mathrm{m} \sim 70 \mu \mathrm{m}$. And when the sulfate corrosion is $90 \mathrm{~d}$, the interfacial microhardness is about $110.7 \mathrm{kgf} / \mathrm{mm}^{2} \sim 161.3 \mathrm{kgf} / \mathrm{mm}^{2}$, and the interfacial transition zone width is about $85 \mu \mathrm{m} \sim 90 \mu \mathrm{m}$. Since the sulphate does not erode the regenerated coarse aggregate, the microhardness of the recycled aggregate remains relatively constant during the erosion process.

The sulfate in the solution and the sulphate inside the recycled concrete react with the hydrated products $\mathrm{Ca}(\mathrm{OH})_{2}$ and C-S-H gels of the cement to form AFt, $\mathrm{CaSO}_{4}$ and TSA. The first two products can be combined with crystal water to form intumescent products, their volume is the original reactant 2.5 times and 1.24 times, which causes the recycled concrete cracking. The latter product can destroy the C-S-H gel in the recycled concrete, which leads to softening and destruction of the recycled concrete, but the early effect is not obvious. The microhardness of the LG-XJ interface of the recycled concrete with sulphate attack for $30 \mathrm{~d}$ is improved and the interfacial transition zone width is reduced. During the preparation of the regenerated coarse aggregate, the surface of the coarse aggregate will produce a large number of fine cracks, so that the interface transition zone forms a loose porous structure. The microhardness of this structure with larger porosity and lower strength is lower, and the interfacial transition zone is larger in microcosmic aspect. In the process of sulfate attack, $\mathrm{SO}_{4}{ }^{2-}$ ions are more likely to enter the interior of the recycled concrete through the weak interface transition zone and react with the large amount of hydrated products at the interface to produce intumescent erosive products such as ettringite. These erosive products mainly play the role of filling the pores, and the deterioration of recycled concrete is not obvious.

With the increase of the age of sulphate, the crystallization pressure in the pores of recycled concrete will continue to accumulate. When the crystallization stress is greater than the ultimate tensile stress of recycled concrete, the expansion cracks will be generated at the LG-XJ interface. When the age of sulphate attack is $60 \mathrm{~d}$, the microhardness value of LG-XJ interface is lower than that of LG-XJ interface with $30 \mathrm{~d}$ age, and the interfacial transition zone width is longer than that of LG-XJ interface. However, compared with the recycled concrete which has not been eroded, the numerical value of the two is not large. This is due to changes in the composition of the interface transition zone, resulting in deterioration of the interface structure. At the same time, the expansion of the crack will accelerate the infiltration of sulfate ions, and the swelling products formed by the sulfate ions involved in the chemical reaction in the regenerated concrete will accelerate the expansion of the 
cracks, making the original pores more likely to be connected pores. This process is repeated alternately, forming a vicious circle. Finally, the structure of the interfacial transition zone becomes fragile and loose, which makes the microhardness value of the LG-XJ interface of the sulfate attack age $90 \mathrm{~d}$ further reduced and the transition zone width is larger. And their rate of change is faster ${ }^{[6,7,8]}$.

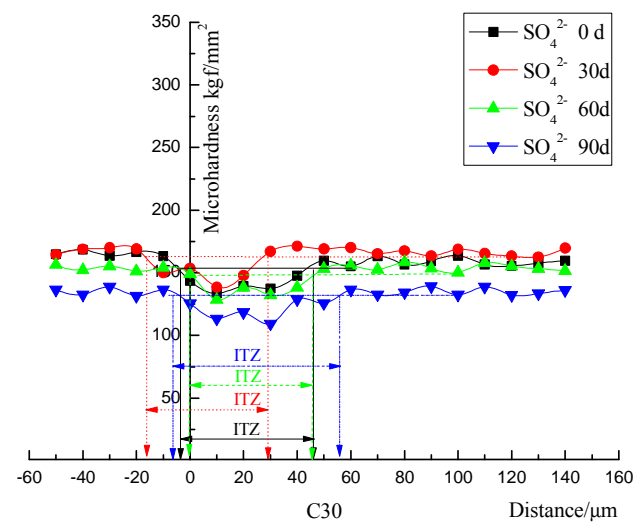

(a)

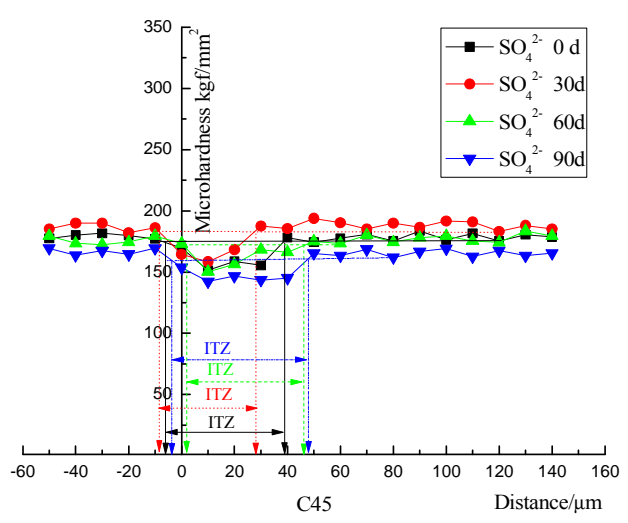

(b)

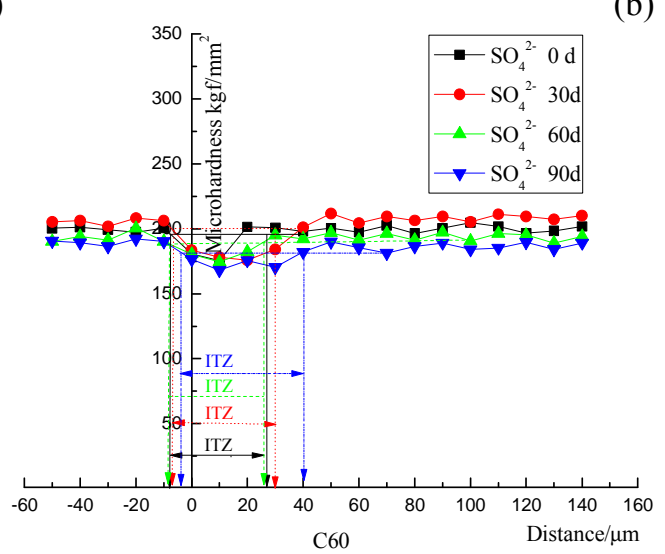

(c)

Fig.4. The variation law of LJ-XJ interface micro hardness of recycled concrete

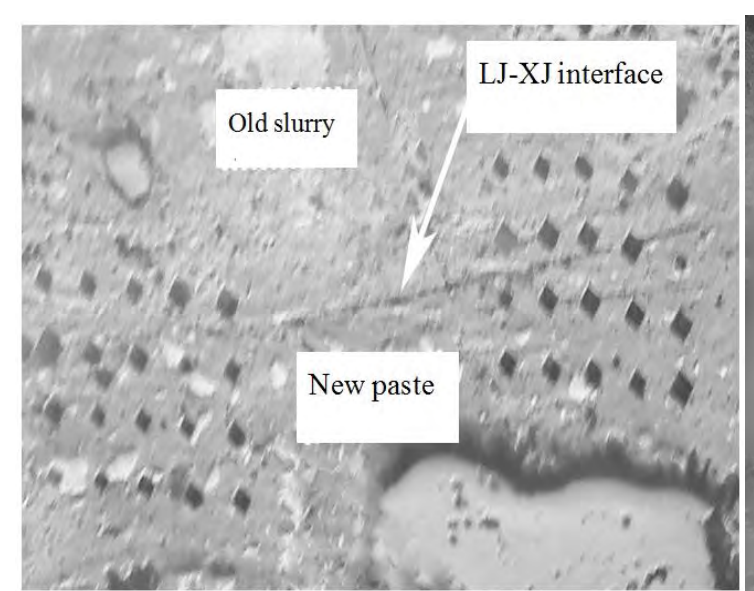

(a) $100 \times$

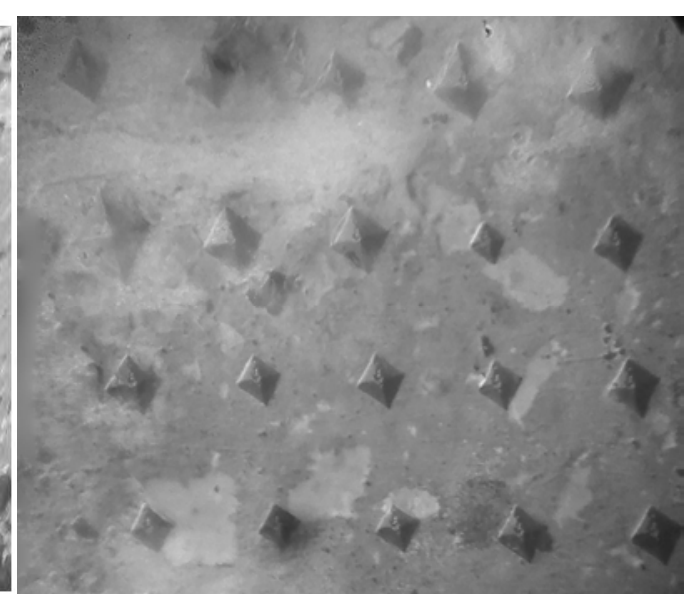

(b) $400 \times$

Fig.5. Optical micrograph of LJ-XJ interface hardness of recycled concrete

The Variation Law of LJ-XJ Interface Microhardness of Recycled Concrete. It can be seen from Fig.4 and Fig.5 that the microhardness of the LJ-XJ interface of the low-strength grade recycled concrete increases first and then decreases, and the interface transition width increases first and then decreases with the growth of the sulfate age. With the increase of sulphate age, the interfacial microhardness of high strength grade recycled concrete increases first and then decreases, and the change of interfacial transition zone width is not obvious. Taking the LJ-XJ interface of C45 as an 
example, the interfacial microhardness is about $151.4 \mathrm{kgf} / \mathrm{mm}^{2} \sim 174.4 \mathrm{kgf} / \mathrm{mm}^{2}$ and the interfacial transition zone is about $40 \mu \mathrm{m} \sim 45 \mu \mathrm{m}$ when the age of sulfate attack is $0 \mathrm{~d}$. The interfacial microhardness is about $158.4 \mathrm{kgf} / \mathrm{mm}^{2} \sim 183.3 \mathrm{kgf} / \mathrm{mm}^{2}$, and the interfacial transition zone width is about $35 \mu \mathrm{m} \sim 40 \mu \mathrm{m}$ when the age of sulphate is $30 \mathrm{~d}$. When the age of sulfate attack is $60 \mathrm{~d}$, the interfacial microhardness is about $150.2 \mathrm{kgf} / \mathrm{mm}^{2} \sim 173.4 \mathrm{kgf} / \mathrm{mm}^{2}$, and the interface transition zone is about $40 \mu \mathrm{m} \sim 45 \mu \mathrm{m}$. And when the age of sulfate attack is $90 \mathrm{~d}$, the interfacial microhardness is about $142.3 \mathrm{kgf} / \mathrm{mm}^{2} \sim 161.9 \mathrm{kgf} / \mathrm{mm}^{2}$, and the interface transition zone is about $50 \mu \mathrm{m} \sim 55 \mu \mathrm{m}$.

As the old mortar pores absorb the cement particles in the new mortar, the new and old mortar can be firmly engaged, so the LJ-XJ interface structure is more compact, and the interface transition zone has a smaller porosity. At the same time, the moisture absorbed by the surface of the old mortar can improve the hydration of the cement particles around the interface and not produce a large water filling space, which can improve the pore structure of the LJ-XJ interface. With the increase in the strength of recycled concrete and the increase in the amount of cement, the interface and cement slurry are structurally more compact and have lower porosity. On the one hand, it can hinder the sulfate ions into the interior of the recycled concrete, while also reducing the number of expansive products in the interface transition zone and cement slurry. On the other hand, due to the increase of ultimate tensile stress of recycled concrete, the expansion stress in the pores is not easy to cause the generation and expansion of fine cracks in the pores. Therefore, the change of microhardness value of LJ-XJ interface of C60 recycled concrete is not significant, and the width of interface transition zone is basically stable. When the age of erosion reached $90 \mathrm{~d}$, both changed. At the same time, the density and porosity of small and medium sized particles in the slurry are obviously lower than those in the interface transition zone. Therefore, in the same sulfate attack environment, the cement slurry is stronger than the interfacial transition zone, and the microhardness of the cement slurry is affected by the erosion level is lower than the interface transition zone.

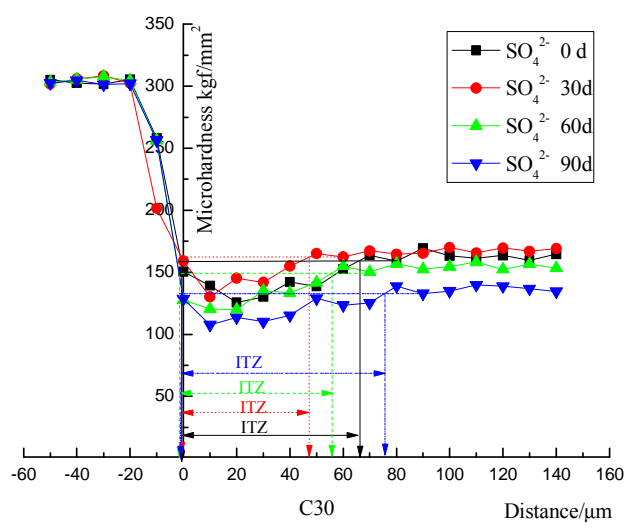

(a)

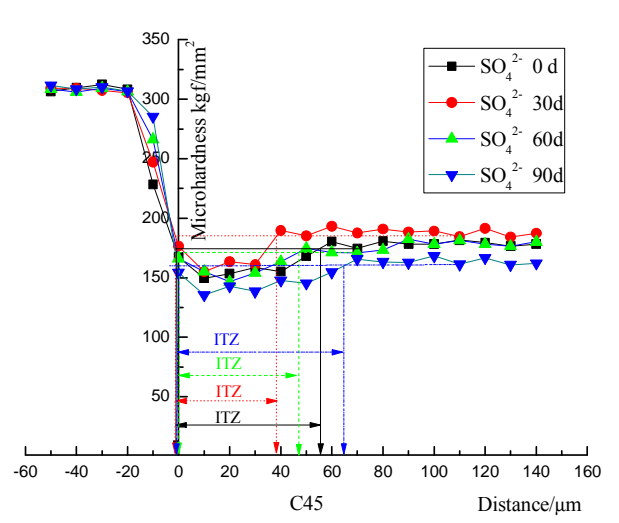

(b)

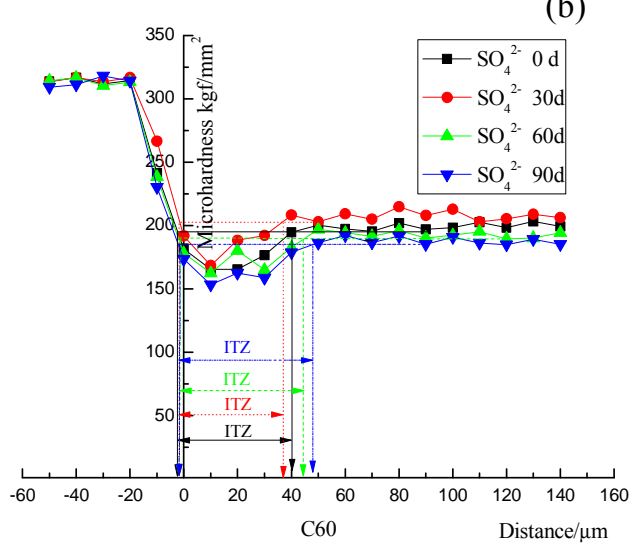

(c)

Fig.6. The variation law of LG-LJ interface micro hardness of recycled concrete 


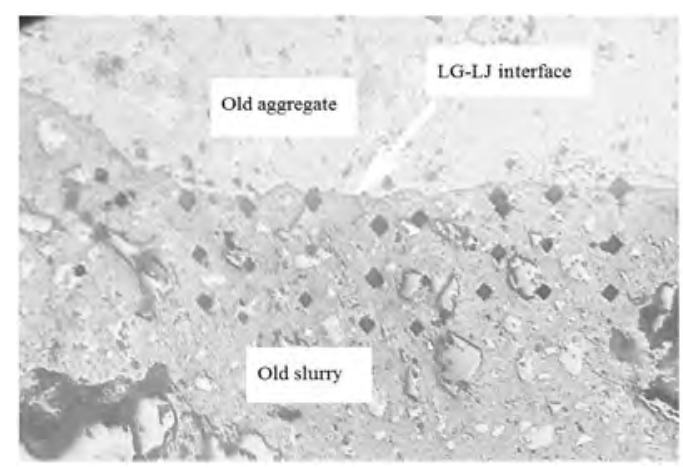

(a) $100 \times$

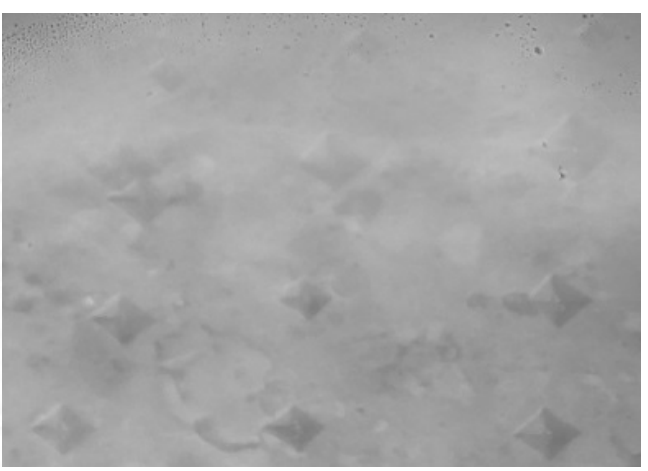

(b) $400 \times$

Fig.7. Optical micrograph of LG-LJ interface hardness of recycled concrete

The Variation Law of LG-LJ Interface Microhardness of Recycled Concrete. LG-LJ interface and LG-XJ interface properties belong to the aggregate - slurry interface. The influence of the sulfate erosion environment on the microhardness and the interfacial transition zone width of the LG-LJ interface are similar to that of the LG-XJ interface. The change of microhardness and interfacial transition zone width of LG-LJ interface is relatively small with the increase of erosion age. As is shown in Fig.6 and Fig.7, the interface hardness of the interface is about $149.6 \mathrm{kgf} / \mathrm{mm}^{2} \sim 174.6 \mathrm{kgf} / \mathrm{mm}^{2}$, and the interfacial transition zone width is about $50 \mu \mathrm{m} \sim 55 \mu \mathrm{m}$ before the sulfate attack. When the sulfate was attacked for 30 days, the interfacial microhardness was about $155.2 \mathrm{kgf} / \mathrm{mm}^{2} \sim 183.3 \mathrm{kgf} / \mathrm{mm}^{2}$, and the interfacial transition zone was about $40 \mu \mathrm{m} \sim 45 \mu \mathrm{m}$. When the age of sulfate attack is $60 \mathrm{~d}$, the interfacial microhardness is about $150.2 \mathrm{kgf} / \mathrm{mm}^{2} \sim 171.3 \mathrm{kgf} / \mathrm{mm}^{2}$, and the interface transition zone width is about $45 \mu \mathrm{m} \sim 50 \mu \mathrm{m}$. And when the age of sulfate attack is $90 \mathrm{~d}$, the interfacial microhardness is about $135.6 \mathrm{kgf} / \mathrm{mm}^{2} \sim 160.9 \mathrm{kgf} / \mathrm{mm}^{2}$, and the interface transition zone width is about $60 \mu \mathrm{m} \sim 65 \mu \mathrm{m}$.

The LG-XJ interface and the LG-LJ interface are similar in nature to the interface of ordinary concrete, but the transition zone of the LG-XJ interface has a loose porous structure with high porosity and low strength. Although the LG-LJ interface transition zone also has fine cracks, but because of the aggregate almost no cracks, so its water absorption is lower than the recycled aggregate, which led to the formation of the interface structure is more compact. In the same sulfate attack environment, the anti-sulfate erosion ability of LG-LJ interface of equivalent strength recycled concrete is better than that of LG-XJ interface. However, compared with the LJ-XJ interface, the LJ-XJ interface has a higher microhardness and a smaller interfacial transition area because the new and old pulp is easier to bite and be structurally more compact. Therefore, in the same strength of recycled concrete, LJ-XJ interface of the sulfate resistance is the strongest ${ }^{[9]}$. With the increase of the grade of recycled concrete, the compactness of recycled concrete will increase and the porosity will decrease. Therefore, both the microhardness of the interface and the width of the interfacial transition or the microhardness of the cement paste itself are reduced by the effect of sulfate attack.

\section{Conclusion}

(1) With the increase of sulphate age, the microhardness of LG-XJ interface and LG-LJ interface increased firstly and then decreased, and the interface transition width decreased first of all and then increased.

(2) With the growth of erosion age, the microhardness of LJ-XJ interface of sulfate-eroded concrete with low strength grade increased firstly and then decreased, and the interface transition width reduced first and then increased. With the increase of sulphate age, the microhardness of LJ-XJ interface of high strength grade recycled concrete heightens and then decreases, while the change of interfacial transition zone width is not significant.

(3) With the increase of the grade of recycled concrete, the compactness of recycled concrete will increase and the porosity will decrease. Therefore, the microhardness of the interface and the width of 
the interfacial transition or the microhardness of the cement paste itself are reduced by the effect of sulfate attack.

\section{Acknowledgement}

National natural science foundation (No: 51378270).

National natural science foundation (No: 51578297).

\section{References}

[1] Li Qiuyi, Quan Hongzhu, Qin Yuan. Recycled aggregate concrete [M]. Beijing: China Building Materials Industry Press, (2011).

[2] Wang Zhangfu, Zhang Jinjian, Zhan Shulin et al. Microscopic analysis of nano scale strengthening technology of recycled aggregate interface [J]. Rare metal materials and engineering, (2010) 39 (2):409-413.

[3] Wu Xuemei, Li Yuan, Guan Zongfu. Study on recycled ceramic concrete and interface [J]. Journal of Zhengzhou University, (2010) 31 (2):35-38.

[4] Geng Jian, Sun Jiaying, Mo Liwei, Zhang Guoliang. Microstructure characteristics of recycled fine aggregate and concrete [J]. Civil engineering and environmental engineering, (2013) 35 (2):135-140.

[5] Li Wengui, Xiao Jianzhuang, Huang Liang et al. Experimental study on the mechanical properties of recycled concrete interface transition zone [J]. Journal of Hunan University, (2014) 41 (12):31-39.

[6] Gao Rundong. Study on micro macro deterioration of sulfate attack on concrete under complex environmen [D]. Beijing: Doctoral Dissertation of Tsinghua University, (2010).

[7] Lu Jianxin, Shui Zhonghe, Tian Sufang et al. Comparative study on Microstructure and properties of super sulfate cement and Portland cement concrete [J]. Journal of Wuhan University of Technology, (2013) 35 (5):1-7.

[8] Jiang Lei, Niu Ditao. Study on damage layer and microstructure of concrete under sulfate attack [J]. Portland bulletin, (2015) 34 (12):462-467.

[9] Xing Zhishui, Deng Min, Wang Aiguo et al. Sulfate attack of concrete due to gypsum aggregate [J]. Journal of building materials, (2014) 17 (1): 30-34.Zhejiang University, (2011). 